\title{
Evaluation of the effect of ERAS to nutritional status of patients with elective craniotomy using bioelectrical impedance analysis: a prospective and randomized controlled trial
}

Jing Yan

Tangdu Hospital of the Air Force Military Medical University

\section{Shasha Wang}

Tangdu Hospital of the Air Force Military Medical University

\section{Yuan Wang}

Tangdu Hospital of the Air Force Military Medical University

Tianzhi Zhao

Tangdu Hospital of the Air Force Military Medical University

\section{Binfang Zhao}

Tangdu Hospital of the Air Force Military Medical University

\section{Shiming He}

Tangdu Hospital of the Air Force Military Medical University

Lin Ye ( $\square$ depnut@fmmu.edu.cn)

Tangdu Hospital of the Air Force Military Medical University

\section{Research}

Keywords: Enhanced Recovery after Surgery, Bioelectrical impedance analysis, Elective craniotomy

Posted Date: February 22nd, 2019

DOl: https://doi.org/10.21203/rs.2.395/v1

License: (a) (1) This work is licensed under a Creative Commons Attribution 4.0 International License. Read Full License 


\section{Abstract}

Background The aim of the present study was to test the body composition changes of patients undergoing elective craniotomy using bioelectrical impedance analysis, so as to evaluate the effect of enhanced recovery after surgery (ERAS) to nutritional status of patients. Methods 140 patients who needed elective craniotomy were randomly divided into two groups: observation group (ERAS group) and control group (traditional treatment group). The age was $45.6 \pm 12.7$ years old. Patients in ERAS group were treated with a set of enhanced recovery measures, while control group patients underwent conventional treatment. Bioelectrical impedance analysis was used to test body composition before and after the surgery. Results The body mass (BM), body mass index (BMI), fat mass (FM), muscle mass (MM), fat mass index (FMI), free-fat mass index (FFMI), body cell mass (BCM), body cell mass index (BCMI), in both groups were decreased after surgery. The decrease of FM and FMI in the control group was significantly different from that in the observation group $(p<0.05)$. However, the decrease of $B M, B M I$, $\mathrm{MM}, \mathrm{FFMI}, \mathrm{BCM}$ and $\mathrm{BCMI}$ in both groups were not statistically significant. Conclusion Patients undergoing elective craniotomy showed various degrees of nutritional injuries, and ERAS could alleviate nutritional injuries caused by operation. Keywords Enhanced Recovery after Surgery $•$ Bioelectrical impedance analysis • Elective craniotomy Trail Registration Chinese Clinical Trial Registry, ChiCTR-INR16009662. Registered on 27 October 2016. Trail Registration Chinese Clinical Trial Registry, ChiCTR-INR16009662. Registered on 27 October 2016.

\section{Background}

Initiated by Professor Henrik Kehlet in 1997, Enhanced Recovery after Surgery (ERAS) programs attempt to attenuate the body's response to surgery, decrease postoperative complications, and shorten the length of hospital stay by optimizing a set of perioperative measures [1]. So far, ERAS has been studied in a variety of surgical specialties, including colorectal surgery [2], pancreaticoduodenectomy [3], gastrectomy [4], et al. Perioperative nutritional status is critical for the surgical patients, and the perioperative nutritional support has been introduced in many guidelines of ERAS [2-4]. Compared with patients undergoing other operations, patients for craniotomy had a low prevalence of malnutrition. Nevertheless, nausea, vomiting, dysphagia, headaches and other symptoms apparently affected normal diet, leading to weight loss or even malnutrition [5].

Changes of nutritional status results in cell membrane change and body fluid imbalance. Therefore, body composition analysis plays an important role in the assessment of nutritional status. Classic parameters includes anthropometric parameters and plasma proteins such as BM, BMI, skinfold thickness, albumin, prealbumin, etc. However, no marker is relatively sensitive or specific. Bioelectrical impedance analysis (BIA) is a quick, safe, inexpensive, noninvasive and especially accurate method to evaluate body composition changes. The principle of BIA involves passing a small multiple-frequency alternating current through the body and measuring the resulting resistance and reactance [6]. 
The aim of this study is to test the body composition changes of patients undergoing elective craniotomy before and after operation, and evaluate the effect of ERAS program to nutritional status of patients. To the best of our knowledge, no studies have investigated nutritional status using BIA within an ERAS program.

\section{Methods}

\section{Patient recruitment}

140 patients who were admitted for elective craniotomy in our hospital between October 2016 and May 2017 were enrolled. Participants were randomly divided into two groups by computerized random number generation: the observation group (ERAS group) $(n=70)$ and the control group (traditional treatment group) ( $n=70)$. Inclusion criteria: All patients between 18 to 65 years of age (18 and 65 were included) without sex limitation, who had a single intracranial lesion, and were medically eligible for elective craniotomy were included. Exclusion criteria: Patients with intracranial trauma, pathology requiring emergent surgery, preoperative disturbance of consciousness, and presence of a confounding condition (e.g., pregnancy) or disease that could potentially impact postoperative recovery (e.g., paralysis, spinal deformity, autoimmune diseases, myocardial infarction, severe infection, liver and renal malfunction, or severe psychological or mental illness) were excluded from this study.

\section{Perioperative measures}

Our study was supported by local institutional ethnical committee to develop a neurosurgical ERAS protocol through a quality patient care initiative. We set up a Neurosurgical ERAS Working Group in June 2016, including clinicians and ancillary staff from neurosurgery, anesthesiology, in-patient and operative nursing and clinical nutrition. This multidisciplinary working group developed and applied the neurosurgical ERAS protocol outlined in this study.

In ERAS group, patients underwent preoperative counseling, stopping smoking and alcohol consumption, nutritional risk screening and nutritional status assessment, nutritional therapy if necessary, antithrombotic prophylaxis, postoperative nausea and vomiting (PONV) management, glycerine enema induction if long history of constipation or $\geq 2$ days without defecation, antimicrobial prophylaxis and skin preparation, shortening preoperative fasting and carbohydrate loading, preoperative respiratory protection, scalp blocks, minimally invasive craniotomies and endoscopic skull base approaches, nonopioid analgesia, avoiding hypothermia, early feeding after surgery, early removal of the urinary drainage within 6 h, rapid de-escalation of fluids, early mobilization[7].

The perioperative care of patients in the conventional care (i.e. control) group was based on traditional neurosurgical protocols. 


\section{Nutritional risk screening (NRS-2002)}

Nutritional status was assessed by NRS2002 [8]. It consists of a nutritional score, a severity of disease score and an age-adjustment for patients aged over 70 years. Nutritional score was calculated as the total score of the nutritional state, severity of disease and the age adjustment. Patients with NRS2002 score $<3$ were classified as having no nutritional risk, and NRS2002 score $\geq 3$ were classified as existing nutritional risk.

\section{Anthropometric measurement and bioelectrical impedance analysis before and after surgery}

Height was measured with an accordant tool accurate to 0.1 centimeter. BIA measurement was taken using Healthy Keeper body composition analyzer (Korea). Patients were on an empty stomach, emptying urine and feces, calming down if exercising or sweating. Shoes, socks and metal accessories were removed. Pelmas attached to the two electrodes while thumb and forefinger squeezed the other two electrodes. Whole-body resistance and reactance between frequencies of $1 \mathrm{kHz}$ and $1 \mathrm{MHz}$ were measured. Body mass (BM), body mass index (BMI), fat mass (FM), free-fat mass (FFM), muscle mass (MM), body fat percentage (BFP), total body water (TBW), intracellular fluid (ICF) and extracellular fluid (ECF) values of patients were recorded. Body fat mass (BCM), fat mass index (FMI) and fat-free mass index (FFMI) were calculated by the following formulas: $\mathrm{FMI}\left(\mathrm{kg} / \mathrm{m}^{2}\right)=\mathrm{FFM}(\mathrm{kg}) / \mathrm{height}^{2}\left(\mathrm{~m}^{2}\right)$, $\mathrm{FFMI}\left(\mathrm{kg} / \mathrm{m}^{2}\right)=(\mathrm{BM}-\mathrm{FM})(\mathrm{kg}) /$ height $^{2}\left(\mathrm{~m}^{2}\right)[9], \mathrm{BCM}(\mathrm{kg})=\operatorname{ICF}(\mathrm{kg}) / 0.7, \mathrm{BCMI}\left(\mathrm{kg} / \mathrm{m}^{2}\right)=\mathrm{BCM}(\mathrm{kg}) /$ height $^{2}\left(\mathrm{~m}^{2}\right)$ [10].

\section{Perioperative nutritional support}

In the ERAS group, patients were permitted solid food 6 hours before surgery and given $400 \mathrm{~mL}$ of $12.5 \%$ carbohydrate-rich beverage 2-3 hours before induction of anaesthesia to whom without suffering diabetes mellitus. The program of early feeding after surgery is as follows: feeding was started 4-6 hours after operation with water, when most of patients revived from anesthesia. During 6-24 hours after operation, patients could drink oral nutritional supplement (250 kcal/day) and other liquid diet. On POD 2, patients were suggested to drink oral nutritional supplement (500 kcal/day) and feed with some soft diet. From POD 3 until discharge, patients were allowed to eat regular diet, and ONS were given only if subjects were unable to eat $1000 \mathrm{kcal} /$ day from normal food. As ONS, we used homogenized diet (Leskon, Xi'an Li Bang clinical nutrition Co, LTD, China). The composition per $100 \mathrm{~mL}$ is: kcal, 104; carbohydrates, $14.6 \mathrm{~g}$; proteins, $4.28 \mathrm{~g}$; lipids, $2.82 \mathrm{~g}$.

While, in control group, fasting is from midnight before surgery, no carbohydrate loading, no early feeding after surgery. Feeding was started $24 \mathrm{~h}$ or more after surgery with the return of passing wind and faeces. 


\section{Discharge criteria}

All the patients in ERAS and control group were discharged if they met our predefined discharge criteria: adequate pain management with oral analgesia, adequate intake of solid food, no need for intravenous fluids, no fever, independent mobility and a safe disposition at home. The decision of discharge was made by the consensus of two senior attending physicians in the department of Neurosurgery, who were instructed to follow the discharging criteria, and were independent of the researchers involved in this study.

\section{Statistical analysis}

All data were analyzed using the SPSS software (version 20.0). Data were shown as mean \pm standard deviation for normally distributed variables and as median for distributed continuous variables. Normally distributed continuous variables were analyzed using paired and un-paired $t$-test and ANOVA. Nonnormally distributed variables were compared by Mann-Whitney U-test test. A two-sided level of $p<0.05$ was considered as statistically significant.

\section{Results}

\section{Clinical characteristics}

A total of 197 patients were assessed for eligibility, prior to enrollment in this study. Fifty-seven patients were excluded for not meeting the inclusion criteria, refusal to participate, refusal to consent for surgery, special physique or refusal to measure after the operation. At last, a total of 140 patients (70 patients in the ERAS group and 70 patients in the control group) patients were enrolled in this study after exclusion, (Oct 2016 - May 2017), 48 patients were male, and 92 were female, with the age of $45.6 \pm 12.7$ years old. The height, BM and BMI were $1.62 \pm 0.06 \mathrm{~m}, 62.0 \pm 9.43 \mathrm{~kg}, 23.7 \pm 3.25 \mathrm{~kg} / \mathrm{m}^{2}$, respectively (Table 1). The height, $B M$ and BMI for ERAS group were $1.62 \pm 0.07 \mathrm{~m}, 61.4 \pm 9.75 \mathrm{~kg}$ and $23.5 \pm 3.39 \mathrm{~kg} / \mathrm{m}^{2}$, while those for control group were $1.62 \pm 0.06 \mathrm{~m}, 64.8 \pm 7.48 \mathrm{~kg}$ and $24.7 \pm 2.34 \mathrm{~kg} / \mathrm{m}^{2}$ (Table 2). There was no statistical difference among age, height, BM and BMI between two groups. All the patients did not have nutritional risk with NRS2002 score $<3$. They underwent craniotomy by the same experienced surgical team, and received allocated intervention. The median total hospital stay were 10 and 13 days respectively in ERAS and control group, and the median postoperative length of stay were 4 and 7 days respectively.

\section{Changes of body composition}

The levels of $\mathrm{BM}, \mathrm{BMI}, \mathrm{FM}, \mathrm{MM}, \mathrm{BCM}, \mathrm{FMI}, \mathrm{FFMI}$ and $\mathrm{BCMI}$ were reduced after surgery in both groups, which were reduced more in the control group (Table 3, Fig.1). The reduction of FM and FMI in ERAS and 
control groups were statistically different $(p<0.05)$ (Fig.1). The reduction of FM and FMI were $(0.16 \pm 1.23)$ vs (0.99 \pm 0.99$) \mathrm{kg}(p=0.017,95 \% \mathrm{Cl}:-1.50$ to -0.15$),(0.06 \pm 0.47) v s(0.38 \pm 0.38) \mathrm{kg} / \mathrm{m}^{2}(p=0.016,95 \% \mathrm{Cl}$ : -0.57 to -0.06$)$ respectively. The reduction of $\mathrm{BM}, \mathrm{BMI}, \mathrm{MM}, \mathrm{BCM}, \mathrm{FFMI}$ and $\mathrm{BCM}$ in these two groups showed no statistical difference, and the Mean \pm SD were $(1.17 \pm 1.20)) v s(2.45 \pm 3.57) \mathrm{kg}(p=0.189$, $95 \% \mathrm{Cl}:-3.27$ to 0.71$),(0.46 \pm 0.47)$ vs $(0.92 \pm 1.32) \mathrm{kg} / \mathrm{m}^{2}$ ( $p=0.203,95 \% \mathrm{Cl}:-1.20$ to 0.28$),(0.95 \pm 1.37)$ vs $(1.43 \pm 2.91) \mathrm{kg}(p=0.541,95 \% \mathrm{Cl}:-2.12$ to 1.15$),(0.64 \pm 6.55)$ vs $(0.94 \pm 2.16) \mathrm{kg}(p=0.860,95 \% \mathrm{Cl}$ : -3.72 to 3.12$),(0.39 \pm 0.57) v s(0.53 \pm 1.18) \mathrm{kg} / \mathrm{m}^{2}$ ( $p=0.485,95 \% \mathrm{Cl}:-0.55$ to 0.26$),(0.25 \pm 0.39) v s(0.37$ $\pm 0.83) \mathrm{kg} / \mathrm{m}^{2}(p=0.414,95 \% \mathrm{Cl}:-0.41$ to 0.17$)$.

\section{Discussion}

In recent years, ERAS program has been widely used in many specialties and formed the expert consensus or guidelines. Nutritional measurement is an important intervention to rapid rehabilitation, including nutritional risk screening, preoperative nutritional support, the use of a carbohydrate-rich isotonic solution preoperatively, restarting early oral feeding within 24 hours postoperatively and postoperative immunonutrition [9][12][13]. Perioperative nutritional support reduces the catabolism, complication rates, and the occurrence of postoperative insulin resistance with a positive impact on perioperative glucose control, muscle preservation and intestinal mucosal function [9][12][13]. Our study, for the first time, tested the body composition changes of patients undergoing elective craniotomy before and after operation, and evaluated the validity of perioperative nutritional support in ERAS program. It also showed that BIA was effective for assessing the nutritional status of patients in ERAS program.

$\mathrm{BM}$ is the most direct, simple and widely used indicator of nutritional status. BMI is another index of nutritional status and a BMI less than 18.5 is considered as malnutrition [14]. Surgery induces "stress response" and activation of the immune-hypothalamic-pituitary-adrenal axis and sympathetic nervous systems, which lead to metabolic changes such as insulin resistance, protein catabolism, and lipid oxidation [15][16][17]. In our study, patients needed elective craniotomy showed a lower prevalence of malnutrition compared with patients undergoing other operations, the control group lost an average of $2.45 \pm 3.57 \mathrm{~kg}$ during perioperative period, while in ERAS group, the weight loss was $1.17 \pm 1.20 \mathrm{~kg}$. In addition, our results indicated that the stress lead to enhanced catabolism. In spite of ERAS program, nutritional status was deteriorated during perioperation. Some studies demonstrated that inflammation caused by acute phase response may often promote a catabolic state, including increased protein decomposition and nitrogen loss, suppressed protein synthesis, and accelerated weight loss, a lower BMI even protein energy malnutrition [18][19][20][21]. Inflammation was also found to be involved in the development of insulin resistance[22]. Previous studies have identified that the preoperative fasting could aggravate the surgical stress response [15], exacerbate insulin resistance [23], and weaken gastrointestinal function [24], leading to aggravation of weight loss. In addition, patients undergoing preoperative overnight fasting were more inclined to be thirsty, hungry, and anxious [23]. Patients in ERAS group undergoing fasting solid food 6 hours before surgery and $12.5 \%$ carbohydrate drinks 2-3 hours 
before induction of anaesthesia were considered to achieve maximal glycogen storage, alleviate insulin resistance, reduce postoperative protein and nitrogen loss, so as to maintain better lean body weight and muscle strength [25][26][27][28]. Furthermore, early feeding postoperatively and oral nutritional supplement are feasible. Previous studies showed that the early oral feeding was effective. Luca Gianotti et al [29] found that patients receiving early oral feeding postoperatively had a more efficient protein synthesis with a higher level of short half-life protein. Early feeding plays a more important role in nourish intestinal mucosa so as to avoid intestinal flora migration rather than providing nutrients for the body. In our study, we performed oral nutritional supplement in the first days after surgery, which possessed a more favorable ratio between volume taken and calorie/protein intake compared with ordinary food. Further more, minimally invasive craniotomies and endoscopic skull base approaches, avoiding hypothermia, early removal of the urinary drainage, early mobilization and other ERAS measures could also alleviate stress response. In our study, the reduction of BM and BMI in the control group was more than that in the ERAS group, suggesting that ERAS program alleviated body catabolism.

$\mathrm{BMI}$ alone cannot differentiate the respective contributions of FM and FFM to body weight, which are main components of body composition. And body weight and BMI are not adequate measurements to assess underlying changes in FM and FFM during illness [30]. Moreover, excess fat mass reduces the sensitivity of BMI to detect nutritional depletion [31]. Therefore, FM was tested. Because FM changes with height, weight, and age, we also calculated FMI, which was height-independent and could provide more meaningful information about nutritional status [8]. Insulin resistance usually means reduced glucose uptake and oxidation and glycogen synthesis [15]. In order to meet elevated energy demands, fat oxidation accelerates and becomes the principle source of fuel postoperatively. Furthermore, increased cortisol and epinephrine levels stimulate gluconeogenesis, with triglycerides being converted to glycerol and fatty acids [15]. Similar to previous reports [30], our results showed a reduced FM and FMI, indicating an increased body fat consumption when suffering stress response. And the reduction of FM and FMI was statistically different between the ERAS and control group, suggesting ERAS program and perioperative nutritional support alleviated stress response and fat catabolism.

Stress response caused by surgery is often accompanied with elevation of protein breakdown and increased nitrogen loss [15]. However, protein intake and synthesis are inadequate because of stress and fasting, which lead to a negative protein balance. Protein breakdown principally involves skeletal muscle protein loss [32]. FFM includes muscle and water, and BCM is the metabolically active component of FFM. Therefore, BCM and FFM are usually considered as better predictors of nutritional status [30][33]. Similar to BMI $\mathrm{FMI}$ and FFMI $\triangle \mathrm{BCMI}$ also eliminates the influence associated with height. It is more sensitive than BMI in monitoring changes in muscle mass and protein in illness-caused abnormality [34] [35]. In addition, it is a prognostic factor of the inflammation status and associated with skeletal muscle [35]. In our study, a decrease in MM, BCM, FFMI and BCMI was observed both in the ERAS and control group, demonstrating the protein breakdown and muscle loss during perioperative period. Compared with the control group, MM, BCM, FFMI and BCMI in ERAS group decreased much less. However, there was no statistically significant difference. We speculate that craniotomy has less influence on gastrointestinal function, compared with other surgeries especially gastrointestinal surgery. Most of the patients in both 
groups could return to normal diet a few days after surgery. In addition, due to changes in intracranial pressure and the residual effects of narcotic drugs, some patients (including ERAS and control group) experienced postoperative nausea and vomiting, and carbohydrate enriched fluid treatment could not reduce postoperative discomfort [36], which affected the recovery of postoperative diet. Although less evidences support the postoperative nutritional support is typically needed for brain tumor patients, with the exception of patients who are in a prolonged comatose state [37], our data demonstrated the validity of ERAS program.

\section{Conclusions}

In summary, we firstly used the bioelectrical impedance method to analyze the changes of body composition in patients undergoing elective craniotomy before and after surgery. Our data showed that the changes of metabolic and nutritional status caused by surgery in ERAS group are less obvious to those in control group, demonstrating that the perioperative nutritional optimization is an essential part of ERAS program, and the application of ERAS in patients undergoing elective craniotomy is safe and effective. Considering the relatively small sample size, our findings warrant further studies on a larger scale.

\section{Abbreviations}

BM: body mass, BMI: body mass index., FM: fat mass, MM: muscle mass, BCM: body cell mass, FMI: fat mass index, FFMI: free-fat mass index, BCMl: body cell mass index.

\section{Declarations}

\section{Acknowledgments}

Special thanks to Dr. Jinge Li, Mr. Kai Yao for their contributions in the management and coordination of the study. Dr. Xingye Zhang, Dr. Yufu Zhang, Dr. Tao Zheng, Dr. Bolin Liu, Dr. Yafei Xue, Dr. Yingxi Wu have make great effort to the medical care service in this study. We appreciated Ms. Xue Jiang, Ms. Lin Ma, Ms. Mingjuan Li, Ms. Lihui Yang, Ms. Fan Yao, Ms. Ye Gao and Ms. Jing Zhang for their great contributions in nursing service.

\section{Funding}

This study is supported by China Natural Science Foundation (81572470 and 81601100$)$. The study design, data collection, statistical analysis, or publications are not influenced by the sponsors and are the exclusive responsibility of the investigators.

\section{Availability of data and materials}

All data generated or analysed during this study are included in this published article. 


\section{Authors' contributions}

LY and SMH were responsible for the conception and design of the study. JY performed the nutritional management in this study, analyzed and interpreted the patient data, and wrote the manuscript. SSW performed the nutritional management and analyzed the patient data. YW, TZZ and BFZ were major contributors in performing ERAS protocol. All authors approved the final version of the manuscript.

\section{Ethics approval and consent to participate}

The review and analysis of patient information for this study was approved by the Ethical Committee of Tangdu Hospital, and complied with the Declaration of Helsinki. Informed consent was obtained from all individual participants included in this study.

\section{Consent for publication}

Not applicable.

\section{Competing interests}

All authors declare that they have no competing interests.

\section{References}

1. Kehlet $\mathrm{H}$. Multimodal approach to control postoperative pathophysiology and rehabilitation. $\mathrm{Br} \mathrm{J}$ Anaesth. 1997;78(5):606-617.

2. Lassen K, Soop M, Nygren J, et al. Consensus review of optimal perioperative care in colorectal surgery: Enhanced Recovery After Surgery (ERAS) Group recommendations. Arch Surg. 2009;144(10):961-969.

3. Lassen K, Coolsen MM, Slim K, et al. Guidelines for perioperative care for pancreaticoduodenectomy: Enhanced Recovery After Surgery (ERAS(R)) Society recommendations. Clin Nutr. 2012;31(6):817830.

4. Jeong O, Park YK, Jung MR, Ryu SY. Compliance with guidelines of Enhanced Recovery After Surgery in elderly patients undergoing gastrectomy. World J Surg. 2017;41(4):1040-1046.

5. McCall M, Leone A, Cusimano MD. Nutritional status and body composition of adult patients with brain tumours awaiting surgical resection. Can J Diet Pract Res.2014;75(3):148-151.

6. Grundmann O, Yoon SL, Williams JJ. The value of bioelectrical impedance analysis and phase angle in the evaluation of malnutrition and quality of life in cancer patients-a comprehensive review. Eur $\mathrm{J}$ Clin Nutr. 2015;69(12):1290-1297.

7. Yuan Wang, Bolin Liu, Tianzhi Zhao, et al. Safety and efficacy of a novel neurosurgical enhanced recovery after surgery (ERAS) protocol for elective craniotomy: a prospective randomized controlled 
trial. J Neurosurg.2018, 22:1-12.

8. Kondrup J, Rasmussen HH, Hamberg O, Stanga Z. Ad Hoc ESPEN Working Group. Nutritional risk screening (NRS 2002): a new method based on an analysis of controlled clinical trials. Clin Nutr. 2003;22:321-336.

9. Vanltallie TB1, Yang MU, Heymsfield SB, Funk RC, Boileau RA. Height-normalized indices of the body's fat-free mass and fat mass: potentially useful indicators of nutritional status. Am J Clin Nutr.1990;52(6):953-959.

10. Talluri T. Qualitative human body composition analysis assessed with bioelectrical impedance. Coll Antropol.1998;22(2):427-432.

11. Mariette Role of the nutritional support in the ERAS programme. J Visc Surg. 2015;152 Suppl 1:S1820.

12. Pogatschnik C, Steiger E. Review of Preoperative Carbohydrate Loading. Nutr Clin Pract. 2015;30(5):660-664.

13. Bozzetti F, Mariani L. Perioperative nutritional support of patients undergoing pancreatic surgery in the age of ERAS. Nutrition. 2014;30(11-12):1267-1271.

14. Anjos LA [Body mass index (body mass.body height-2) as indicator of nutritional status in adults: review of the literature]. Rev Saude Publica.1992;26(6):431-436.

15. Weissman C: The metabolic response to stress: An overview and update. Anesthesiology. 1990;73:308-327.

16. Bateman A, Singh A, Kral T, Solomon S. The immune-hypothalamic-pituitary-adrenal axis. Endocr Rev. 1989;10(1):92-112.

17. Gillis C, Carli F. Promoting perioperative metabolic and nutritional care. Anesthesiology. 2015;123(6):1455-1472.

18. Kaysen GA. Malnutrition and the acute-phase reaction in dialysis patients-how to measure and how to distinguish. Nephrol Dial Transplant. 2000;15(10):1521-1524.

19. Flores EA, Bistrian BR, Pomposelli JJ, Dinarello CA, Blackburn GL, Istfan NW. Infusion of tumor necrosis factor/cachectin promotes muscle catabolism in the rat. A synergistic effect with interleukin 1. J Clin Invest. 1989;83(5):1614-1622.

20. Bergström J, Lindholm B. Malnutrition, cardiac disease, and mortality: an integrated point of view. Am J Kidney Dis. 1998; 32(5):834-841.

21. Desborough JP. The stress response to trauma and surgery. Br J Anaesth. 2000;85(1):109-117.

22. Yoshikawa T, Noguchi Y, Doi C, Makino T, Nomura K. Insulin resistance in patients with cancer: relationships with tumor site, tumor stage, body-weight loss, acute-phase response, and energy expenditure. Nutrition. 2001;17(7-8):590-593.

23. Ljungqvist 0 . Modulating postoperative insulin resistance by preoperative carbohydrate loading. Best Pract Res Clin Anaesthesiol. 2009;23(4):401-409. 
24. McClave SA, Heyland DK. The physiologic response and associated clinical benefits from provision of early enteral nutrition. Nutr Clin Pract. 2009;24(3):305-315.

25. Crowe PJ, Dennison A, Royle GT. The effect of pre-operative glucose loading on postoperative nitrogen metabolism. Br J Surg. 1984;71(8):635-637.

26. Svanfeldt M, Thorell A, Hausel J, et al. Randomized clinical trial of the effect of preoperative oral carbohydrate treatment on postoperative whole-body protein and glucose kinetics. Br J Surg. 2007;94(11):1342-1350.

27. Yuill KA, Richardson RA, Davidson HI, Garden OJ, Parks RW. The administration of an oral carbohydrate-containing fluid prior to major elective upper-gastrointestinal surgery preserves skeletal muscle mass postoperatively-a randomised clinical trial. Clin Nutr. 2005;24(1):32-37.

28. Henriksen MG, Hessov I, Dela F, Hansen HV, Haraldsted V, Rodt SA. Effects of preoperative oral carbohydrates and peptides on postoperative endocrine response, mobilization, nutrition and muscle function in abdominal surgery. Acta Anaesthesiol Scand. 2003;47(2):191-199.

29. Gianotti L, Nespoli L, Torselli L, Panelli M, Nespoli A. Safety, feasibility, and tolerance of early oral feeding after colorectal resection outside an enhanced recovery after surgery (ERAS) program. $J$ Colorectal Dis. 2011;26(6):747-753.

30. Kyle UG, Morabia A, Slosman DO, Mensi N, Unqer P, Pichard C. Contribution of body composition to nutritional assessment at hospital admission in 995 patients: a controlled population study. $\mathrm{Br} \mathrm{J}$ Nutr. 2001;86(6):725-731.

31. Kyle UG, Pirlich M, Lochs H, Schuetz T, Pichard C. Increased length of hospital stay in underweight and overweight patients at hospital admission: a controlled population study. Clin Nutr. 2005;24(1):133-142.

32. Downey RS, Monafo WW, Karl IE, Matthews DE, Bier DM. Protein dynamics in skeletal muscle after trauma: local and systemic effects. 1986;99(3):265-274.

33. Kawaguchi T, Taniguchi E, Itou M, et al. Body cell mass is a useful parameter for assessing malnutrition and severity of diseas in non-ascitic cirrhotic patients with hepatocellular carcinoma or esophageal varices. Int J Mol Med. 2008;22(5):589-594.

34. Talluri A, Liedtke R, Mohamed El, Maiolo C, Martinoli R, De Lorenzo A. The application of body cell mass index for studying muscle mass changes in health and disease conditions. Acta Diabetol. 2003;40 Suppl 1: S286-289.

35. Rondanelli M, Talluri J, Peroni G,et al. Beyond Body Mass Index. Is the Body Cell Mass Index (BCMI) a useful prognostic factor to describe nutritional, inflammation and muscle mass status in hospitalized elderly? Body Cell Mass Index links in elderly. Clin Nutr. 2017;pii: S0261-5614(17)301127.

36. Karlsson A, Wendel K, Polits S, Gislason H, Hedenbro JL. Preoperative Nutrition and Postoperative Discomfort in an ERAS Setting: A Randomized Study in Gastric Bypass Surgery. Obes Surg. 2016;26(4):743-748. 
37. Hagan KB, Bhavsar S, Raza SM, et al. Enhanced recovery after surgery for oncological craniotomies. J Clin Neurosci.2016;24: 10-16.

\section{Tables}

Table 1 Clinical characteristics of the study sample at admission*

\begin{tabular}{lllll}
\hline & Overall $(\mathrm{n}=140)$ & Male $(\mathrm{n}=48)$ & Female $(\mathrm{n}=92)$ & $P$ value \\
\hline Age (years) & $45.6 \pm 12.7$ & $45.2 \pm 13.3$ & $45.7 \pm 12.5$ & 0.939 \\
Height $(\mathrm{m})$ & $1.62 \pm 0.06$ & $1.69 \pm 0.05$ & $1.59 \pm 0.04$ & 0.000 \\
$\mathrm{BM}(\mathrm{kg})$ & $62.0 \pm 9.43$ & $68.1 \pm 9.50$ & $59.7 \pm 8.36$ & 0.000 \\
$\mathrm{BMI}\left(\mathrm{kg} / \mathrm{m}^{2}\right)$ & $23.7 \pm 3.25$ & $23.9 \pm 3.26$ & $23.7 \pm 3.27$ & 0.274 \\
\hline
\end{tabular}

*Values are mean \pm standard deviation

Abbreviations: BM: body mass, BMI: body mass index.

Table 2 patient characteristics of the study sample at admission*

\begin{tabular}{lllll}
\hline & Overall $(\mathrm{n}=140)$ & ERAS group $(\mathrm{n}=70)$ & Control group $(\mathrm{n}=70)$ & $P$ value \\
\hline Age $(\mathrm{years})$ & $45.6 \pm 12.7$ & $45.4 \pm 12.0$ & $46.1 \pm 11.9$ & 0.864 \\
Height $(\mathrm{m})$ & $1.62 \pm 0.06$ & $1.62 \pm 0.07$ & $1.62 \pm 0.06$ & 0.834 \\
$\mathrm{BM}(\mathrm{kg})$ & $62.0 \pm 9.43$ & $61.4 \pm 9.75$ & $64.8 \pm 7.48$ & 0.205 \\
$\mathrm{BMI}\left(\mathrm{kg} / \mathrm{m}^{2}\right)$ & $23.7 \pm 3.25$ & $23.5 \pm 3.39$ & $24.7 \pm 2.34$ & 0.208 \\
\hline
\end{tabular}

*Values are mean \pm standard deviation

Abbreviations: BM: body mass, BMI: body mass index.

Table 3 Changes of body composition before and after surgery 


\begin{tabular}{|c|c|c|c|c|c|}
\hline \multirow[t]{2}{*}{ Parameters } & \multicolumn{2}{|c|}{ ERAS group $(n=70)$} & \multicolumn{2}{|c|}{ Control group $(n=70)$} & \multirow{2}{*}{\begin{tabular}{l}
\multicolumn{1}{c}{$P$ value } \\
Changes of parameters during \\
hospitalization
\end{tabular}} \\
\hline & Admission & Discharge & Admission & Discharge & \\
\hline $\mathrm{BM}(\mathrm{kg})$ & $61.4 \pm 9.74$ & $60.2 \pm 9.56$ & $64.8 \pm 7.48$ & $62.4 \pm 6.2$ & 0.189 \\
\hline $\begin{array}{l}\text { BMI } \\
\left(\mathrm{kg} / \mathrm{m}^{2}\right)\end{array}$ & $23.5 \pm 3.39$ & $23.1 \pm 3.28$ & $24.7 \pm 2.34$ & $23.8 \pm 1.99$ & 0.203 \\
\hline $\mathrm{FM}(\mathrm{kg})$ & $18.2 \pm 4.80$ & $18.1 \pm 4.88$ & $19.8 \pm 3.38$ & $19.6 \pm 3.40$ & 0.017 \\
\hline MM (kg) & $40.1 \pm 7.25$ & $39.2 \pm 7.04$ & $42.1 \pm 6.48$ & $40.7 \pm 5.10$ & 0.541 \\
\hline $\mathrm{BCM}(\mathrm{kg})$ & $30.6 \pm 5.22$ & $29.9 \pm 5.03$ & $31.8 \pm 4.34$ & $30.9 \pm 3.39$ & 0.860 \\
\hline $\begin{array}{l}\text { FMI } \\
\left(\mathrm{kg} / \mathrm{m}^{2}\right)\end{array}$ & $7.1 \pm 2.06$ & $7.0 \pm 2.10$ & $7.5 \pm 1.58$ & $7.2 \pm 1.50$ & 0.016 \\
\hline $\begin{array}{l}\mathrm{FFMl} \\
\left(\mathrm{kg} / \mathrm{m}^{2}\right)\end{array}$ & $16.4 \pm 2.12$ & $16.1 \pm 1.97$ & $17.1 \pm 1.83$ & $16.6 \pm 1.32$ & 0.485 \\
\hline $\begin{array}{l}\mathrm{BCMI} \\
\left(\mathrm{kg} / \mathrm{m}^{2}\right)\end{array}$ & $11.7 \pm 1.43$ & $11.4 \pm 1.36$ & $12.1 \pm 1.12$ & $11.7 \pm 0.81$ & 0.414 \\
\hline
\end{tabular}

*Values are mean \pm standard deviation

Abbreviations: BM: body mass, BMl: body mass index., FM: fat mass, MM: muscle mass, BCM: body cell mass, FMl: fat mass index, FFMI: free-fat mass index, BCMl: body cell mass index

\section{Figures}



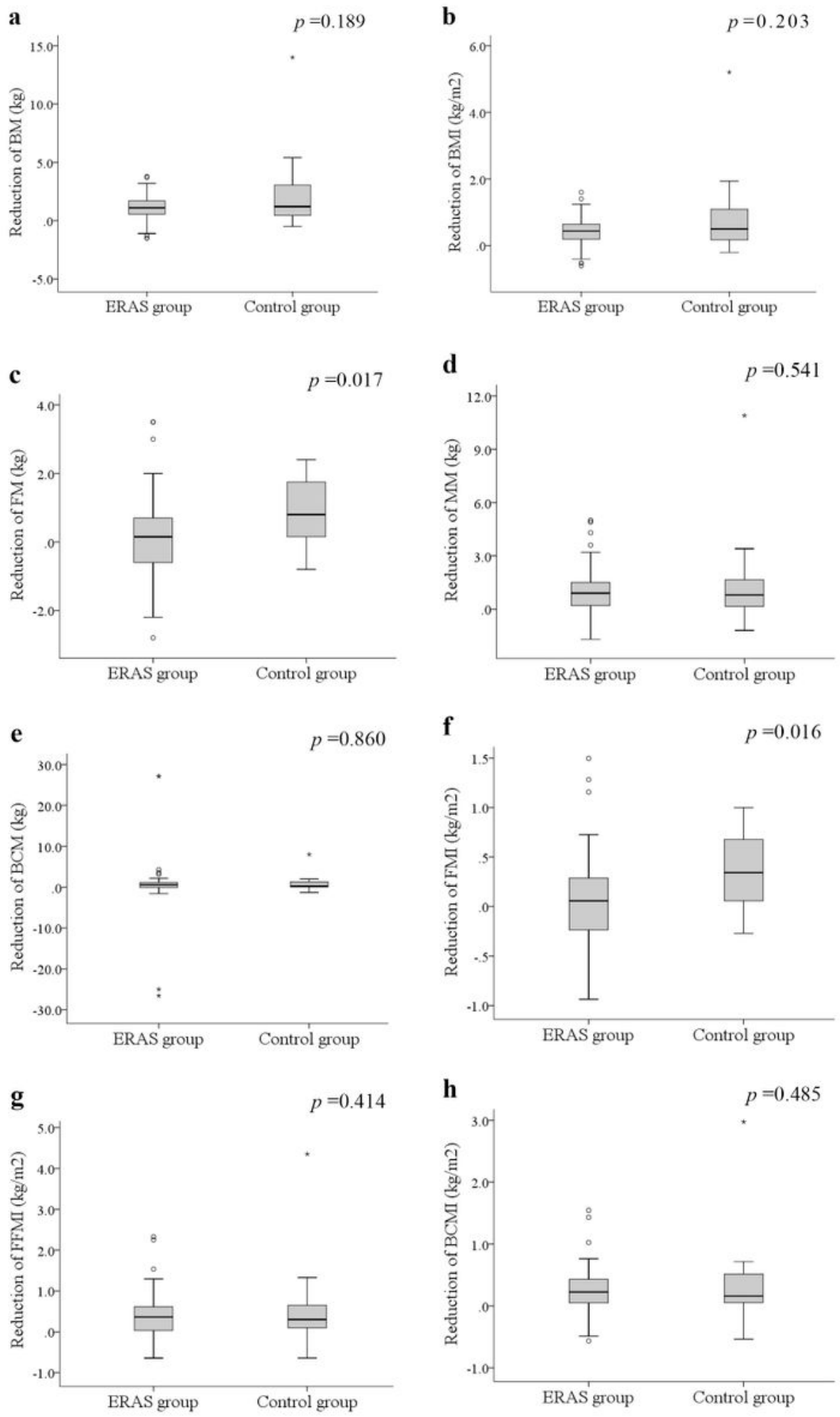

\section{Figure 1}

Changes of body composition for patients in control and ERAS group before and after surgery. (a-h) boxplots showing the parameters with statistical difference. (a). reduction of BM (kg). (b). reduction of $B M I(k g / m 2)$. (c). reduction of FM (kg). (d). reduction of MM $(\mathrm{kg})$. (e). reduction of BCM (kg). (f). reduction of FMI ( $\mathrm{kg} / \mathrm{m} 2)$. (g). reduction of FFMI $(\mathrm{kg} / \mathrm{m} 2)$. (h). reduction of BCMI $(\mathrm{kg} / \mathrm{m} 2)$. 


\section{Supplementary Files}

This is a list of supplementary files associated with this preprint. Click to download.

- supplement1.docx

- supplement2.doc 